\title{
Функционально-смысловой потенциал некоторых знаков препинания в русских научно-технических текстах
}

Ключевые слова: кавычки, скобки, тире, специальный текст, акцентирующая функция. Key words: quotation marks, brackets, dash, special text, accentuating function.

\section{Abstract}

The paper considers the use of quotation marks, brackets, and hard hyphen as the paragraphic means which control comprehension of a reader of science and technology sources. In addition, the article determines and describes accentuating function of the punctuation marks.

Письменная фиксация речи, как известно, предусматривает использование определенной системы знаков препинания, призванных содействовать смысловому, синтаксическому и интонационному членению текста. Выполняя свое основное предназначение, русская пунктуация способна, по словам Н.С. Валгиной, «при творческом ее использовании» превращаться в «мощное смысловое и стилистическое средство» [Valgina 2001: 240]. Совершенно закономерно, что знаки препинания наряду с другими параграфическими средствами (пробелами, разрядкой, символикой, надстрочными знаками и т.д.) играют немаловажную роль в восприятии печатного текста, его доступности и понятности.

Владение визуальной грамотностью (термин Н.Л. Шубиной), предполагающей способность к прочтению изобразительных, типографских конфигураций и распознаванию функций используемых в тексте знаков и средств, особенно актуально при восприятии гибридных (креолизованных) текстов, в том числе научных и учебных. По мнению ученых, адекватное восприятие не только вербального содержания, но и графического оформления научных текстов является залогом плодотворного участия «в научной дискуссии (в том числе и заочной)», требующей внимательного прочтения научного текста, что 
в свою очередь «предполагает точное понимание не только используемых терминов, но и способов организации материала» [Šubina 2006: 13].

Изучение особенностей применения знаков препинания в научных и научно-технических текстах, несмотря на отдельные исследования в этой области (см., например: [Gavrilova 2009, 2017; Evtušenko 2012; Kuznecova 2015; Pristajko 1998; Ubušueva 2008]), в наши дни еще только начинается, что делает обращение к заявленной теме актуальным. Описание инвентаря и функций параграфических средств управления пониманием научного текста, будучи обусловленным «потребностью современного общества в эффективной трансляции научных знаний» [Gavrilova 2009: 5], может, с одной стороны, определенным образом способствовать выбору оптимальных способов пунктуационного оформления содержания пишущим, а с другой - содействовать решению некоторых теоретических вопросов, касающихся статуса пунктуационной системы в условиях современной письменной, в том числе и научной, коммуникации.

Цель нашей публикации - на материале учебно-научных текстов по металлургии выявить и описать функционально-смысловые возможности таких полифункциональных знаков препинания, как кавычки, скобки и тире. В задачи исследования входит а) анализ текстовых манифестаций, демонстрирующих использование отмеченных знаков препинания как коннотативных параграфических средств, управляющих пониманием читателя; б) выявление и идентификация основных функций этих знаков.

Материалом для исследования послужили более 580 контекстов, извлеченных приемом сплошной выборки из двух источников общим объемом 863 стр. [NPD, MTM]. Исследование осуществлялось с помощью описательного метода, включающего приемы наблюдения, интерпретации и классификации, контекстуального анализа и приема количественных подсчетов.

В основе нашего подхода к анализу особенностей функционально-смыслового использования рассматриваемых знаков в специальном тексте положена концепция функциональных типов терминологической номинации, обоснованная нами в работе [Pristajko 1996]. В соответствии с предложенной концепцией в специальных текстах обнаруживаются такие типы терминологической номинации, как интродуктивная (вводная), классифицирующая, дефинитивная, повторно-отождествляющая и др., реализующиеся в соответствующих контекстах. При этом представление терминологических единиц может носить акцентирующий и неакцентирующий характер. При акцентированном представлении термина в контекстах присутствуют разного рода словесные или графические маркеры (комментарии определенного рода, кавычки, скобки и т.д.), призванные привлечь усиленное внимание читающего к представляемому объекту [Pristajko 1996: 125]. Отмеченное позволяет говорить об акцентирующей функции знаков препинания, анализ реализации которой в специальных текстах и является основным предметом 
данной публикации, продолжающей наши исследования, результаты которых изложены в статье [Pristajko 1998].

Предварительно отметим, что количественно среди средств параграфического акцентирования в проанализированных нами источниках преобладают скобки, использованные в 483 случаях, что составляет $83 \%$ от числа всех проанализированных контекстов, на долю кавычек приходится 12\% (70 конт.) и 5\% (29 конт.) - на долю тире. Несмотря на такое количественное соотношение рассматриваемых знаков, начнем изложение с рассмотрения кавычек.

Употребление кавычек в русском языке, как известно, может носить как регулярный, типичный, так и нерегулярный, факультативный характер. В последнем, интересующем нас случае кавычки используются при употреблении слов и выражений в необычном, ироническом или ином ситуативно-контекстуальном значении [Rozental' 1989: 158-162]. Обобщая случаи факультативного использования кавычек, Б.С. Шварцкопф говорит о кульминативном (выделяется контекст, требующий внимания), переносном (выделяется единица в метафорическом или метонимическом значении), модальном (выделяется негативно-оценочная, ироническая, условная, неточная номинация) и метаязыковом (выделяется чуждая контексту единица) применении этого знака [Švarckopf 1997: 374-375]. Предложенная типология получила развитие в статьях [Zaliznâk 2007; Pučkova 2011 и др.].

Мы же, как уже было заявлено выше, относим все случаи нерегулярного, факультативного использования кавычек к общей функции акцентирования внимания читателя, охватывающей как кульминативную, так и модальную, метафорическую и метаязыковую функции.

Анализ 70 контекстов, содержащих лексические единицы, преднамеренно, как мы полагаем, выделенные с помощью кавычек, позволил, прежде всего, установить два вида употребления кавычек в акцентирующей функции: 1) для выделения лексико-номинативных единиц, несущих специальную информацию, и 2) для выделения лексем общеупотребительного, неспециального характера.

Акцентированные («закавыченные») лексико-номинативные единицы, отмеченные в контекстах первого типа, далеко не однородны по своему лексико-семантическому статусу, что позволяет, в свою очередь, предположить существование различных мотивов, побуждающих авторов к выделению тех или иных слов с помощью кавычек. Наиболее частотными единицами этой группы, по нашим данным, являются профессионализмы - некодифицированные, в отличие от терминов, обозначения специальных понятий. По своему функционально-семантическому статусу они наиболее близки терминам и так же, как и последние, часто сопровождаются дефинитивными контекстами, толкующими обозначаемое понятие. Сигналом, свидетельствующим о принадлежности таких единиц к разговорной сфере профессионального обозначения, могут быть не только кавычки, но и скобки, и авторский комментарий типа 
«как говорят», «как иногда называют» и т.п. Приведем несколько примеров: $\mathrm{Ha}$ практике наиболее распространена схема получения плоских заготовок так называемой «бегущей» волной детонации [NPD: 187]; Подлежащие сварке стержни зажимают в «губках" машины [MТМ: 370]; Левая ветвь кривой соответствует созданию совершенных бездислокационных нитевидных кристаллов (так называемых «усов»), прочность которых близка к теоретической [МТМ: 60].

Следующий пласт лексики первой группы составляют авторские термины, появившиеся в ходе теоретических или экспериментальных разработок научных вопросов. Как правило, такие авторские термины сопровождаются разного рода указаниями на авторство и соответствующими дефинициями, принятыми авторами по отношению к ним. Например: Дислокащии воздействуют друг на друга, мешают друг другу перемещаться, происходит их аннигиляция (взаимное уничтожение), что позволило Дж. Гордону образно назвать их взаимодействие в проиессе пластической деформаџии «интимной жсизнью дислокаций» [MTM: 61].

Специальную информацию содержат и разнообразные метафорические номинации, к которым авторы обращаются для того, чтобы нагляднее, точнее обозначить предмет, явление или процесс, о которых идет речь. Появление метафор в качестве средств номинации в специальных текстах вполне закономерно и оправдано объективными условиями существования и развития языка науки [Gusev 1978]. Чаще всего коннотативный заряд метофорической номинации осознается самим автором текста, который не только заковычивает, но и комментирует такой термин, ср.: Некоторые материалы проявляют как мгновенную, так и замедленную реакиию на нагрузку. Это свойство образно называют «памятью» металлов [NPD: 22].

Все единицы первой группы могут быть объединены общим понятием предтерминов, квазитерминов, терминов в стадии становления [Grinëv-Grinevič 2008: 44-47]. Очевидно, что именно промежуточное положение таких единиц между словами-нетерминами и официальными общепринятыми терминами и является первоначальной причиной маркирования таких слов в тексте с помощью кавычек. По отношению к терминологическим номинациям этого подтипа невозможно однозначно идентифицировать конкретные функции акцентирования, так как большинство профессионализмов и предтерминов разного вида, в том числе и авторских терминов, образованы переносным, метафорическим способом, т.е. выполняют метафорическую функцию, в то же время им присуща и метаязыковая функция, поскольку они «чужды» или непривычны контексту, в который включены.

С такой же «диффузностью» частных функций акцентирования мы сталкиваемся и при рассмотрении контекстов, в которых кавычки применяются для выделения слов второй группы, а именно: неспециальных, общеупотребительных. В этом случае метафорическая функция нередко сопрягается 
с модальной, поскольку использованное в переносном значении общеупотребительное слово указывает на условный, приблизительный характер номинации, ср.: Напряжения ... делают схему напряженно-деформированного состояния более "мягкой»... [NPD: 71]; ...nорошок прокатывали на специальном прокатном стане, получая "сырую» полосу [NPD: 251]; образеч деформируется без заметного увеличения нагрузки («течет») [MTM: 86]; Сварщик манипулирует дугой руками, вводя их в камеру через специальные герметические "рукава» [МТМ: 361].

При повторном использовании условного обозначения автор может снять кавычки, очевидно, полагая, что читатель уже ознакомился с языком описания, ср.: К числу мер борьбы с деформациями при сварке относятся различного рода закрепления, ... «обратный» выгиб свариваемых элементов и т.д. ... Недостаточная эффективность закреплений ... привела к применению обратных выгибов изделия перед сваркой [МТМ: 387].

Перейдем к анализу особенностей акцентирования читательского внимания с помощью скобок и тире и рассмотрим последовательно случаи, характеризующиеся а) вариативностью или б) индивидуализированным характером применения этих знаков.

Согласно нашим данным, параллельное, вариантное использование в специальных текстах скобок или тире в качестве акцентирующего средства наблюдается прежде всего как прием конкретизации при репрезентации родовых и следующих за ними видовых наименований, ср.: Исходные заготовки - слитки или штабики - подвергают горячей обработке давлением для повышения пластичности [NPD: 67]; Повышение рабочих параметров машин (давлений, скоростей, температур) обусловливает создание новых конструкиионных материалов [МТМ: 490].

С помощью тире или скобок может выделяться термин, следующий после дефинитивного контекста, ср.: ...nри охлаждении образуется твердая пористая масса - агломерат [МТМ: 14]; Все большее распространение получает способ создания высоких давлений энергией высоковольтного разряда в жидкости (электрогидравлическое деформирование металлов)... [NPD: 185], а также аббревиатура после полного аналога, ср.: Анализ ... степени использования ресурса пластичности (СИРП) ... позволяет наметить пути совершенствования технологических режимов прессования [NPD: 68]; Основным показателем работы доменной печи является коэффициент использования полезного объема - КИПО [МТМ: 19].

Отметим, что во всех рассмотренных случаях предпочтение отдается скобкам. В частности, по нашим данным, число контекстов, предъявляющих гиперонимы и их видовые наименования с помощью скобок, почти в 10 раз превышает число соответствующих контекстов с использованием тире. Возможности тире как акцентирующего средства исчерпываются описанными выше случаями. 
Скобки же применяются еще как минимум в двух случаях: при введении в изложение синонимических (вариантных) номинаций и конкретизирующей информации.

Способ подачи вариантных средств номинации одного и того же объекта с помощью скобок является для специальных текстов типичным, хотя и не единственным. По нашему мнению, в основе такой одновременной презентации синонимических терминов лежит стремление авторов показать стихийно сложившуюся вариантность обозначений и помочь читателю сориентироваться в существующем терминологическом разнобое. Оставляя один из терминов перед скобками, в которые заключаются все остальные наименования данного специального объекта, автор тем самым определяет и свою позицию в сложившейся терминологической ситуации, отдавая предпочтение «заскобочному» термину и таким образом приглашая читателя разделить его точку зрения. Ср.: Для материалов, используемых при высоких температурах, основными характеристиками являются жаростойкость (окалиностойкость) и жаропрочность [MTM: 214].

Достаточно часто в скобках размещаются формулы, дается расшифровка символьного обозначения, ср.: Электрокорунд представляет собой кристаллический оксид алюминия ( $\left.\mathbf{A l}_{2} \boldsymbol{O}_{3}\right)$ [MTM: 486]; При накатывании зубчатых колес ... воспроизводится защепление пары зубчатых колес с заданным

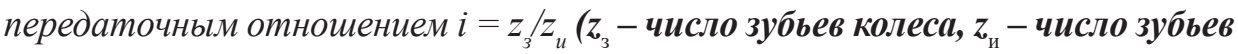
инструмента) [MTМ: 500].

По нашим данным, предъявление вариантных наименований отмечено в одной трети «скобочных» контекстов, включающих и случаи заключения в скобки аббревиатуры после полного наименования.

В остальных «скобочных» контекстах этим способом предъявляется разного рода конкретизирующая информация, дополнительно интерпретирующая сказанное ранее. Рассмотрим виды конкретизации, характерные для научно-технического текста.

Наиболее часто в скобки заключаются видовые наименования к гиперониму, которые могут сопровождаться словами например, к примеру. Ср.: Волочение проволоки осуществляют в фильерах, изготовленных из твердых сплавов (например, карбида вольфрама)... [NPD: 306]. В единичных случаях гипоним и гипероним меняются местами, ср.: Непрерывная прокатка прутков (проволочных заготовок) является производительным способом получения проволоки [NPD: 318]. К этим же случаям можно отнести презентацию номенклатурных знаков, ср.: Внутренняя поверхность труб контролируется соответствующими приборами (например, РВП-457 и др.) [NPD: 297].

Конкретизирующая вставка, оформленная скобками, может содержать точные, в том числе и числовые данные. Ср.: Сначала загружают металлический лом (до 20-30\% от массы плавки) [МТМ: 22]; Размеры изготовляемых изделий ограничены двумя измерениями (высотой и шириной)... [NPD: 79]. 
Поясняя положение вещей, автор в скобках может указывать на причинно-следственные связи (За пределами очага деформации температура резко снижается (из-за нарушения теплового контакта) [NPD: 108]), на цель или назначение того, о чем говорится (...алюминий, армированный стекловолокном (для топливных пластин реакторов) [NPD: 341]), способ или орудие действия (...на рабочую поверхность кокиля наносят огнеупорное покрытие (кистью или пульверизатором) [МТМ: 300]), необходимое условие (...в основном используют газовую защчту сварочной ванны от контакта с воздухом (при небольшом количестве шлака) [МТМ: 379]), давать этимологический комментарий (...линию начала затвердевания называют линией ликвидус (лат. liquidus - жнидкий), линию конца затвердевания - линией солидус (лат. solidus - твердый) [МТМ: 110]).

В целом же уточняющая информация может быть самой разной по содержанию и может сопровождаться дополнительным комментарием: иногда, чаще, как правило, в большинстве, в (некоторых) случаях и др., ср.: Температура нагрева соединяемьх деталей (чаще всего с помощью индуктора) должна составлять $T_{n л}$ [МТМ: 374].

Еще одним подвидом конкретизации, осуществляемой с помощью скобок, можно считать размещение в скобках толкований или дефиниций, раскрывающих суть обозначаемого, ср.: Измельчение зерен и увеличение их удельной (приходящейся на единицу объема) поверхности связано со снижением удельной концентрации примесей... [NPD: 68]; Основныли свойствами формовочных и стержневых смесей являются: газопроницаемость (способность смеси пропускать газы), газотворность (способность нагретой смеси выделять zазы )... [МТМ: 288]. Нередко порядок следования дефиниции и термина меняется: Все большее распространение получает способ создания высоких давлений энергией высоковольтного разряда в жидкости (электрогидравлическое деформирование металлов)... [NPD: 185]; ...образуется карбид железа (цементит) [МТМ: 18].

Как видим, с помощью конкретизации, поясняя положение вещей, автор ясно и неоднозначно доносит до сведения читателя научную информацию.

Как показало проведенное исследование, специфика использования скобок, кавычек и тире в акцентирующей функции заключается прежде всего в том, что их «работа» в качестве средств актуализации и активизации читательского внимания осуществляется одновременно на различных текстовых уровнях: графическом - они визуально выделяют тот или иной фрагмент предложения, привлекая к нему внимание; лексико-синтаксическом - с помощью этих знаков, в частности тире и скобок, могут выделяться, обособляться определенные синтаксические единицы (вводные слова и словосочетания, вставные, пояснительные и присоединительные конструкции и пр.); концептуальном - выделяемые посредством этих знаков контексты, как правило, содержат специальную информацию (чаще всего дефиниции) 
или же включают лексико-номинативные единицы, обозначающие специальные понятия (термины, предтермины, профессионализмы, номенклатурные знаки и т.д.).

Спектр использования кавычек, скобок и тире в качестве акцентирующего средства специальной письменной речи достаточно широк. Можно говорить о разной степени загруженности этих знаков при выполнении ими акцентирующей функции: наиболее ярко и разнообразно последняя проявляется при использовании скобок и кавычек, в меньшей степени - при использовании тире. Это, очевидно, обусловлено тем, что тире в любых, в том числе и специальных, текстах имеет более значительную синтаксическую нагрузку, являясь системным пунктуационным знаком при обособлении определений и предложений, выделении однородных членов предложения; в некоторых видах простых и сложных предложений и т.д., что затрудняет в таких случаях констатацию у этого знака особой акцентирующей функции, так как она совпадает в таких контекстах с выделительной функцией тире.

Отметим также, что использование кавычек в акцентирующей функции носит более индивидуализированный характер, в большей степени отражает авторские намерения, чем употребление в той же функции скобок и тире. В то же время применение скобок и тире в качестве акцентирующего средства, в сопоставлении с аналогичным использованием кавычек, отличается более системным характером, а также вариантностью, возможностью замены скобок на тире и наоборот.

\section{Источники}

MTM: Solncev Û.P. (ed.), 1988, Metallovedenie i tehnologiâ metallov, učeb. dlâ vuzov, Moskva: Metallurgiâ.

NPD: Kolikov A., Poluhin P., Krupin A. i dr., 1986, Novye processy deformirovaniâ metallov i splavov: učeb. posobie dlâ vuzov, Moskva: Vysšaâ škola.

\section{Литература}

Evtušenko T.G., 2012, Punktuacionno-grafičeskie sredstva v sovremennyh russkih naučnyh tekstah: sostav, funkcionirovanie, avtoref. dis. [...] kand. filol. nauk: 10.02.01 - russkij âzyk, Tomsk.

Gavrilova A.A., 2009, Upravlenie ponimaniem čitatelâ naučnogo teksta s pomoŝ' $\hat{u}$ metatekstovyh sredstv (na materiale naučnyh tekstov russkogo i nemeckogo âzykov), avtoref. dis. [...] kand. filol. nauk, Saratov.

Gavrilova A.A., 2017, Metatekstovye èlementy v naučnom tekste, Saratov: Saratov. Social'no-èkonom. in-t (filial) RĖU im. G.V. Plehanova.

Grinëv-Grinevič S.V., 2008, Terminovedenie, Moskva: Akademiâ.

Gusev S.S., 1978, Metafora kak sredstvo svâzi različnyh komponentov âzyka nauki, Filosofskie nauki, 2, pp. 70-75. 
Kuznecova E.A., 2015, Skobki v tekste pravovogo dokumenta kak lingvokognitivnyj fenomen, Vestnik MGOU. Seriâ: Russkâ̂ filologiâ, 3, pp. 37-43.

Pristajko T.S., 1996, Leksiko-nominativnaâ organizaciâ special'nogo teksta, monografiâ, Dnepropetrovsk: UKO İMA-Press.

Pristajko T.S., 1998, Akcentiruûsaâ funkciâ znakov prepinaniâ v special'nom tekste, Vissnik Dnipropetrovs'kogo universitetu. Seriâ: Movoznavstvo, iss. 3, pp. 83-87.

Pučkova E.V., 2011, Kavyčki kak sredstvo vyraženiâ konnotacii v naučnom tekste, Učenye zametki TOGU, vol. 2, № 2, pp. 80-85, https://elibrary.ru/item.asp?id=22662197; 20.12.2019.

Rozental' D.Ė., 1989, Spravočnik po pravopisaniû i literaturnoj pravke, Moskva: Kniga.

Šubina N.L., 2006, Punktuaciâ sovremennogo russkogo âzyka, Moskva: Akademiâ.

Švarckopf B.S., 1997, «Â postavil kavyčki potomu, čto...» [in:] Oblik slova, sbornik statej pamâti Dmitriâ Nikolaeviča Šmeleva, Moskva: Russkij âzyk. Kursy, pp. 374-381.

Ubušueva V.V., 2008, Semantičeskie funkcii tire v amerikanskih naučnyh tekstah XX v., Vestnik TGU, 11 (67), pp. 212-216.

Valgina N.S., 2001, Aktivnye processy v sovremennom russkom âzyke, učebn. posobie, Moskva: Logos.

Zaliznâk A.A., 2007, Semantika kavyček, Trudy Meždunarodnogo seminara «Dialog 2007» po komp'ûternoj lingvistike i eë priloženiâm, Moskva, http://www.philology. ru/linguistics2/zaliznyak_anna-07.htm; 12.11.2019. 